\title{
Constituição do acervo da biblioteca da penitenciária de Florianópolis
}

\author{
Constitution of the Florianopolis penitentiary library acquis
}

\author{
Amabile Costa \\ Mestranda em Ciência da Informação pela Universidade Federal de Santa Catarina - UFSC. \\ Diretora de Marketing e Divulgação da Associação Catarinense de Bibliotecários. \\ E-mail: amabilecosta.m@gmail.com
}

\begin{abstract}
Camila Monteiro de Barros Doutora e Mestre em Ciência da Informação pela Universidade Federal de Santa Catarina - UFSC. Professora do Departamento de Ciência da Informação e do Programa de Pós-Graduação em Ciência da Informação da Universidade Federal de Santa Catarina - UFSC.

E-mail: camila.c.m.b@ufsc.br
\end{abstract}

\section{Resumo}

O presente estudo trata da dissertação em andamento intitulada "Constituição do acervo da Biblioteca da Penitenciária de Florianópolis, tendo como objetivo geral analisar a constituição do acervo da biblioteca da Penitenciária de Florianópolis. A pesquisa caracteriza-se como qualitativa, documental e exploratória, para alcançar alguns objetivos específicos, utilizou-se a Análise de Conteúdo proposta por Bardin para analisar os dados coletados. Em relação a fundamentação teórica, as legislações sobre a educação e as bibliotecas prisionais em âmbito nacional são apresentadas, bem como, a leitura e o acervo dentro dos espaços de privação de liberdade. No que concerne aos resultados parciais, percebe-se que diversas temáticas são contempladas no acervo, a Biblioteca da Penitenciária de Florianópolis utiliza o software Biblivre para gerenciar seu acervo e aplica a Classificação Decimal Universal para procedimentos de classificação.

Palavras-chave: Biblioteca prisional. Análise de Bardin. Desenvolvimento de coleção.

\begin{abstract}
The present study deals with the dissertation in progress entitled "Constitution of the Florianópolis Penitentiary Library collection, having as its general objective to analyze the constitution of the Florianópolis Penitentiary Library collection. A research demonstrated how qualitative, documentary and exploratory, to achieve some specified objectives, used in Content Analysis proposed by Bardin to analyze the collected data. In relation to the theoretical basis, as laws on education and libraries approved at the national level are prohibited, as well as reading and the collection within the spaces of deprivation of liberty. Not applicable to partial results, it is clear that several themes are covered in a collection, a Florianópolis Penitentiary Library that uses the Library software to manage its collection and applies the Universal Decimal Classification for classification procedures.
\end{abstract}

Keywords: Prison library. Bardin analysis. Collection development. 


\section{Introdução}

No Brasil, as leis referentes à educação e às bibliotecas dentro dos espaços de privação de liberdade são: a Lei de Execução Penal (LEP) nº 7210 - 11 de julho de 1984, que apresenta detalhadamente os direitos e deveres dos reeducandos ${ }^{1}$ e do Estado; a Lei Federal $n^{\circ} 12.433$ 29 de junho de 2011, que sanciona a remição da pena pelo estudo ou pelo trabalho; a Recomendação n ${ }^{\circ} 44$ de 2013, do Conselho Nacional de Justiça, que institui a Remição de Pena pela Leitura e a Lei Federal n ${ }^{\circ} 13.163$ - de 9 de setembro de 2015, que sanciona o ensino médio dentro das penitenciárias. Ressaltamos que as leis são autenticadas para garantir os direitos de cada cidadão, portanto, seu cumprimento é essencial.

Com base nas experiências da primeira autora desta pesquisa podemos afirmar que a realidade, em alguns casos, não condiz com a literatura e/ou legislação. No período em que a autora realizou seu estágio curricular obrigatório, foi possível observar que a população das penitenciárias é composta por presos provisórios, que teoricamente deveriam estar aguardando julgamento dentro das cadeias públicas. Além disso, o Banco Nacional de Monitoramento das Prisões (CNJ, 2018) mostra que a maioria dos presos que estão em espaços de privação de liberdade, ainda estão sem condenação.

Salienta-se que os estabelecimentos prisionais possuem o dever de reintegração, orientação e direção dos reeducandos para o convívio em sociedade (SILVA NETO; LEITE, 2011). Em conformidade com Conrad (2012, p. 411, tradução nossa ${ }^{2}$ ) as bibliotecas prisionais irão proporcionar enormes "benefícios para os presos, incluindo materiais úteis para utilizar em seu tempo livre, reabilitação, educação e ajuda na transição para o mundo exterior". Também têm como propósito, apoiar os projetos educacionais de cada unidade, a necessidade de leitura e possivelmente tornar-se centro de referência. Outro papel da biblioteca prisional é suprir as questões legais, como por exemplo, a LEP nº 7210 de 1984 e a Recomendação nº 44 de 2013 Remição de Pena pela Leitura, que serão especificados na próxima seção.

\footnotetext{
${ }^{1}$ Para esta pesquisa, utilizar-se-á os substantivos no gênero masculino, conforme as regras estabelecidas pela língua portuguesa, além disso, para que os leitores compreendam quais estabelecimentos trabalham com o público feminino e masculino. Porém, a autora tem consciência que "existe um uso sexista da língua na expressão oral e escrita (nas conversações informais e nos documentos oficiais) que transmite e reforça as relações assimétricas, hierárquicas e não equitativas que se dão entre os sexos em cada sociedade e que é utilizado em todos os seus âmbitos" (FRANCO; CERVERA, 2006, p. 5).

2 Texto original: "Reading how an activity can bring tremendous benefits to prisoners, including useful ways to use their time, rehab, education, and help in transitioning to the outside world"(CONRAD, 2012, p. 411).
} 
O universo desta pesquisa é composto pelo Complexo Penitenciário de Florianópolis, localizado no bairro Agronômica. Este Complexo é composto pelas seguintes unidades: Casa Velha; Penitenciária Estadual de Florianópolis; Presídio Masculino; Presídio Feminino; Hospital de Custódia e Tratamento Psiquiátrico (HCTP); Casa do Albergado; Centro de Observação e Triagem (COT); Centro de Triagem da Trindade (CTT); Unidade Básica de Saúde (UBS) e Companhia de Policiamento e Guarda (COSTA, 2017).

A presente pesquisa está voltada para a constituição dos acervos da Biblioteca da Penitenciária de Florianópolis. De acordo com Vergueiro (1989) a constituição dos acervos deve ser realizada pela política de desenvolvimento de coleção, onde acontece o planejamento cíclico das atividades elaboradas por meio de metodologias e ações que irão envolver todo o acervo de uma biblioteca. Ressalta-se que cada tipo de biblioteca deve possuir sua política de desenvolvimento de coleção com ênfase em suas especificidades.

Após as considerações supracitadas, a questão de pesquisa é: Qual a constituição do acervo da biblioteca da Penitenciária de Florianópolis? Tendo como objetivo geral analisar a constituição do acervo da biblioteca da Penitenciária de Florianópolis, elencamos os seguintes objetivos específicos: a) Descrever as condições gerais do ambiente e do acervo; b) Caracterizar as temáticas contempladas no acervo; c) Mapear a proveniência do acervo; d) Conhecer os critérios de seleção do acervo e e) Propor diretrizes para o desenvolvimento desse acervo.

Vale destacar que é essa pesquisa está sendo desenvolvida no Programa de PósGraduação em Ciência da Informação da Universidade Federal de Santa Catarina (PGCIN UFSC), no âmbito da linha de pesquisa Organização, Representação e Mediação da Informação, vinculada ao eixo Organização e Preservação do Conhecimento.

A escolha desta temática está imbricada às experiências vivenciadas pela pesquisadora, durante o período de sua graduação, desde seu vínculo ao "Programa Novos Horizontes: a Universidade nos espaços de privação de liberdade"3, desde 2016 até a presente data como pesquisadora associada e a realização do Estágio Curricular obrigatório na biblioteca da Penitenciária de Florianópolis. Fruto destas experiências foi o Trabalho de Conclusão de Curso (TCC) sobre a temática, intitulado "Biblioteca da Penitenciária de Florianópolis: um espaço sociocultural e educativo" apresentado no curso de Biblioteconomia Habilitação em Gestão da

\footnotetext{
${ }^{3}$ Coordenado de 2016-2017 pela professora doutora Geysa Spitz Alcoforado de Abreu vinculada ao departamento de Pedagogia da UDESC. Logo em seguida, coordenado de 2018 até 2019 pela professora doutora Daniella Camara Pizarro vinculada ao departamento de Biblioteconomia da UDESC.
} 
Informação na Universidade do Estado de Santa Catarina (UDESC) em 2017, orientado pela Professora Doutora Daniella Camara Pizarro.

A contribuição desta discussão para a comunidade científica envolve evidenciar aspectos sobre a comunidade carcerária ${ }^{4}$ e os estabelecimentos prisionais, e aproximar essa realidade e suas particularidades principalmente das áreas de Biblioteconomia e Ciência da Informação. As bibliotecas prisionais estão inseridas em espaços extremamente vulneráveis do ponto de vista social em que a segurança está em primeiro lugar, que a censura pode estar presente e as temáticas solicitadas podem ser as mais diversas possíveis. Além disso, a presente dissertação foi financiada pela Coordenação de Aperfeiçoamento de Pessoal de Nível Superior (CAPES), órgão de fomento das pós-graduações brasileiras.

\section{Contexto histórico das prisões e bibliotecas prisionais no Brasil}

A Declaração Universal dos Direitos Humanos reforça no artigo 19 que todas as pessoas possuem o direito de opinar e expressar-se, para isso deverão ter acesso às informações necessárias por qualquer meio e sem censura alguma (ONU, 1948, p. 6). Pressupõe-se que as bibliotecas prisionais irão suprir a necessidade informacional dos reeducandos disponibilizando materiais sem censura, e dentro dos padrões de segurança, para a comunidade carcerária e cumprindo as legislações brasileiras, visto que o direito aplicado ao reeducando é a restrição de ir e vir, portanto, a informação deve chegar a qualquer pessoa privada de liberdade, é um direito.

A Lei de Execução Penal (LEP) no 7210, de 11 de julho de 1984 sanciona os deveres e direitos que os reeducandos possuem dentro do sistema prisional, igualmente os deveres e os direitos do Estado para com os reeducandos. A Lei veio para que as punições fossem focadas em um viés humanizado (ALMEIDA, 2014). Porém, salienta-se que o sistema prisional brasileiro não parece estar caminhando pelo viés humanizado. É fácil perceber essa afirmação a partir das manchetes de jornais e revistas, bem como os artigos que relatam as violências e retaliações que ocorrem dentro do sistema prisional. Para Rangel $(2014$, p.1) "[...] o sistema penitenciário brasileiro está falido - não cumpre seu papel ressocializador, não há individualização do cumprimento da pena, e não comporta todos os que para lá são enviados -

\footnotetext{
${ }^{4}$ Comunidade carcerária nesta dissertação refere-se aos reducandos.
} 
a sociedade se cala diante dessa realidade, por acreditar que os que lá estão merecem tal sofrimento".

Em relação ao título II, capítulo II, as assistências são deveres do Estado para com o reeducando. Das diversas seções presentes neste capítulo, destacaremos a seção V da assistência educacional, sancionada no seu artigo 21 que prevê: "Em atendimento às condições locais, dotar-se-á cada estabelecimento de uma biblioteca, para uso de todas as categorias de reclusos, provida de livros instrutivos, recreativos e didáticos” (BRASIL, 1984, p. 3).

Na Constituição da República Federativa do Brasil de 1988 está sancionado o direito de todas as pessoas, assim como dos poderes legislativo, judiciário e executivo, meio ambiente, entre outros. Para essa pesquisa, alguns pontos deste documento foram elencados, tais como, o artigo cinco afirma que "todos são iguais perante a lei, sem distinção de qualquer natureza, garantindo-se aos brasileiros e aos estrangeiros residentes no País a inviolabilidade do direito à vida, à liberdade, à igualdade, à segurança e à propriedade” (BRASIL, 2016, p. 13).

Em 1994, o governo brasileiro sanciona a resolução n ${ }^{\circ} 14$ de 11 de novembro de 1994 que reforça as regras mínimas para os presos no Brasil. As regras foram criadas pela ONU e publicadas a partir do primeiro Congresso das Nações Unidas sobre prevenção do crime e tratamento de delinquentes em 1955.

O Decreto n 6.049 sancionado em 27 de fevereiro de 2007 dispõe o Regulamento Penitenciário Federal, esse decreto também é dividido em capítulos, títulos, artigos e incisos. No título $\mathrm{V}$ é evidenciada a assistência ao preso e ao egresso, no artigo 25, incisos quatro e cinco apresentam informações sobre as bibliotecas e livros. O inciso quatro afirma que o estabelecimento penal contará com bibliotecas para uso dos reeducandos e seu acervo deverá ser composto por materiais nacionais e estrangeiros, técnicos, jurídicos, didáticos e recreativos (BRASIL, 2007). Já o inciso cinco, declara que os estabelecimentos penais poderão realizar parcerias com "órgãos ou entidades, públicos ou particulares, visando à doação por estes entes de livros ou programas de bibliotecas volantes para ampliação de sua biblioteca" (BRASIL, 2007, p. 4).

A Lei Federal n 12.433 , de 29 de junho de 2011 sanciona a alteração da Lei de Execução Penal $n^{0} 7.210$ "para dispor sobre a remição de parte do tempo de execução de pena por estudo e por trabalho" (BRASIL, 2011). A Lei explicita todos os direitos dos reeducandos em relação a remição, nesse caso ainda não entra a Lei de Remição de Pena pela Leitura. De acordo com 
Brasil (1984) em relação a remição da pena por estudo o reeducando que estiver em regime fechado ou semiaberto poderá remir de 1 dia de pena a cada 12 horas de frequência nas salas de aula. Já o reeducando que está em regime aberto poderá estudar fora do estabelecimento prisional, mas deverá apresentar mensalmente o seu índice de aproveitamento escolar. Em relação a remição por meio do trabalho, a cada três dias de trabalho, um dia de pena é remido.

Em 2011, o decreto 7.626 “institui o Plano Estratégico de Educação no âmbito do Sistema Prisional" brasileiro (BRASIL, 2011). O artigo cinco deste decreto afirma que o Ministério da Educação deverá "promover a distribuição de livros didáticos e a composição de acervos de bibliotecas nos estabelecimentos penais" (BRASIL, 2011, p. 1). A Recomendação n 44 de 2013 conhecida como Lei da Remição de Pena pela Leitura, prevê "sejam valoradas e consideradas as atividades de caráter complementar, assim entendidas aquelas que ampliam as possibilidades de educação nas prisões, tais como as de natureza cultural, esportiva, de capacitação profissional, de saúde, entre outras” (BARBOSA, 2013).

A Lei Federal $n^{\circ}$ 13.163, de 9 de setembro de 2015 modifica novamente a Lei de Execução Penal n 7.210 "para instituir o ensino médio nas penitenciárias", declara que os reeducandos receberão os cursos supletivos de Educação de Jovens e Adultos (EJA). No artigo 21-A desta Lei, inciso quatro sanciona que o censo penitenciário deverá apurar a existência de bibliotecas e as condições deste acervo (BRASIL, 2008).

Alguns estabelecimentos prisionais brasileiros dispõem de espaços para armazenar os materiais de suas bibliotecas. Essas unidades não contam com uma política de desenvolvimento de coleção e nem com o cargo de bibliotecário dentro do sistema prisional (CARVALHO; CARVALHO, 2017). Para Carvalho e Carvalho (2017, p. 148) as bibliotecas prisionais brasileiras "têm objetivo de estimular a leitura, assegurar a democratização do acesso aos livros, assim como servir de apoio para aqueles que estudam dentro das prisões". Neste sentido, programas que incentivam a leitura estão presentes dentro das penitenciárias brasileiras, por exemplo, em São Paulo existem clubes de leituras com produção de resenhas e engajamento das livrarias (CARVALHO; CARVALHO, 2017).

No Brasil, as bibliotecas prisionais estão espalhadas pelas cinco regiões: sul, sudeste, centro-oeste, norte e nordeste. Em 2016, foi lançado o livro intitulado "A visão do Ministério Público sobre o Sistema Prisional Brasileiro”, com dados coletados em 2005. O material conta com diversas temáticas relacionadas ao sistema prisional, tais como quantidade de estabelecimentos prisionais, quantidade de vagas, quantidade de unidades que disponibilizam 
uniformes, materiais de higiene, entre outros. Uma das perspectivas do livro é em relação as bibliotecas prisionais e o seguinte panorama geral foi apresentado:

a) A região Sul possuía um total de 122 bibliotecas prisionais, sendo, 28 do Paraná; 46 de Santa Catarina e 68 do Rio Grande do Sul.

b) A região Sudeste contava com 300 bibliotecas prisionais, consistindo em, 29 no Espírito Santo; 86 em Minas Gerais; 38 no Rio de Janeiro e 147 em São Paulo.

c) A região Centro-Oeste dispunha de 74 bibliotecas prisionais, equivalente a 6 no Distrito Federal; 20 em Goiás; 27 no Mato Grosso do Sul e 21 no Mato Grosso.

d) A região Nordeste detinha de 70 bibliotecas prisionais, sendo, 2 em Alagoas; 14 na Bahia; 12 no Ceará; 6 no Maranhão; 9 na Paraíba; 15 em Pernambuco; 5 no Piauí; 3 no Rio Grande do Norte e 4 em Sergipe.

e) A região Norte, apresentava, 70 bibliotecas prisionais, consistindo em 9 no Acre; 9 na Amazônia; 1 no Amapá; 18 no Pará; 14 em Rondônia; 1 em Roraima e 7 em Tocantins.

Percebe-se que a região Sudeste é a que mais contém bibliotecas prisionais, provavelmente por ter também o maior número de estabelecimentos prisionais inspecionados pela pesquisa, cerca de 481. Enquanto Sul teve 193, Centro-Oeste 237, Nordeste 382 e Norte 159 (CONSELHO NACIONAL DO MINISTÉRIO PÚBLICO, 2016).

\section{Leitura e acervo: a mediação dentro dos espaços de privação de liberdade}

A leitura dentro dos espaços de privação de liberdade, torna-se possível o desenvolvimento da empatia por meio de questões apresentadas nas obras disponibilizados. Além disso, proporciona aos reeducandos a ampliação do seu vocabulário por meio das novas palavras apresentadas nos materiais consultados. A leitura apresenta diversos resultados de interação, tais como, "informação que vem da folha, dos conhecimentos internalizados, sejam eles especificamente linguísticos, sejam de conhecimento de mundo ou enciclopédicos que se vão entrelaçando" (PELANDRÉ, 2009, p. 106). Neste sentido, a leitura pode ampliar o desenvolvimento do raciocínio e aprendizagem cognitiva dos reeducandos, bem como, diminuir os níveis de ansiedade. Román (2018, p. 44) afirma que há uma concordância entre "acadêmicos e intelectuais, de diferentes tipos e disciplinas, de que a leitura nas prisões favorece e encoraja os presos a acelerar de forma frutífera o processo de reintegração social”. Esses aspectos têm 
implicação direta nos mecanismos de ressocialização, objetivo principal da execução das penas que, conforme prevê a LEP, serve para a "harmônica integração social do condenado e do internado" (BRASIL, 1984, p. 1).

Envolto nessa perspectiva de leitura, Almeida Júnior e Bortolin (2007) afirmam que o leitor possui a responsabilidade proporcional ao autor de determinado material, já que cada pessoa interpreta de uma forma aquilo que lê. Essa interpretação vem a partir da maturidade, vivências e experiências do leitor, portanto, dependendo do nível em que o leitor se encontra, é necessário a presença de um mediador.

A leitura apresenta diversos resultados de interação, tais como, "informação que vem da folha, dos conhecimentos internalizados, sejam eles especificamente linguísticos, sejam de conhecimento de mundo ou enciclopédicos que se vão entrelaçando (PELANDRÉ, 2009, p. 106). Evidencia-se que cada leitor possui suas particularidades perante ao ato de ler, isso decorre do nível educacional proposto, as habilidades adquiridas a partir das suas experiências de vida, as expectativas a partir de cada conteúdo lido, além disso, o momento em que o leitor vive, o seu sentimento, por exemplo. Assim sendo, "a leitura é um processo de interação dinâmica entre o leitor e o texto, no qual os atos estimulados pelo texto fogem ao controle do próprio texto, dando origem ao surgimento da criatividade" (GOMES, 2008, p. 10).

Para entender a necessidade informacional e o conhecimento adquirido pela comunidade que a biblioteca atenderá, é preciso entender as condições de vida presente nessas ambiências. Portanto, é fundamental saber as "condições objetivas, como salário, o emprego, a moradia, sejam as condições subjetivas, como a história de cada grupo, suas lutas, organização, conhecimento, habilidades, enfim, sua cultura" (PELANDRÉ, 2009, p.17).

No contexto atual em que a sociedade está inserida, a informação "tem um papel relevante e crucial no processo de construção do conhecimento. Isso torna necessário ao homem organizar sua vida a partir do tipo de informação a que tem acesso" (MALAQUIAS, 1999, p. 14-15). A biblioteca prisional atuará como agente de disseminação e mediação da informação disponibilizada a comunidade carcerária, assim conscientizando a "sua [dos reeducandos] condição de ser no mundo e configurar um conceito de cidadania” (MALAQUIAS, 1999, p. $15)$.

Para Gomes (2008, p.1) a informação é composta por conhecimento "comunicado que pode ser retomado no esforço de revisão e reflexão que subsidiam a construção de novos 
conhecimentos ou reconstrução daqueles já estabelecidos". O processo da construção do conhecimento está envolto com a interação proposta entre o estabelecimento e o indivíduo que participa desse projeto. A interação, neste contexto, compreende os suportes e formatos disponibilizados aos leitores, bem como a estrutura do estabelecimento, a disposição e preservação de seu acervo, além do acesso aos materiais.

\section{Procedimentos metodológicos}

Para alcançar os objetivos, a pesquisa foi caracterizada da seguinte forma. Em relação aos seus objetivos, a pesquisa é exploratória; sobre os procedimentos técnicos é uma pesquisa documental e da forma de abordagem do problema caracteriza-se como uma pesquisa qualitativa.

Com intuito de alcançar os objetivos a) descrever as condições gerais do ambiente e do acervo e b) caracterizar as temáticas contempladas no acervo, foi realizada uma visita à biblioteca da Penitenciária de Florianópolis no segundo semestre de 2019, as informações foram levantadas por meio de um guia de observação.

No que tange aos objetivos c e d, quais sejam: c) mapear a proveniência do acervo e d) conhecer os critérios de seleção do acervo, foram realizadas entrevistas por meio de google forms com três questionários diferentes: um voltado para as pessoas que estavam ligadas a ações voltadas para à educação dentro do Complexo Penitenciário de Florianópolis, um para as pessoas ligadas as atividades da biblioteca deste estabelecimento e outro para as pessoas vinculadas à segurança do estabelecimento. O questionário foi enviado para dez pessoas colaboradores que atuam com essas temáticas dentro da instituição, 4 pessoas envolvidas com os aspectos da educação, 3 agentes prisionais e 3 pessoas envolvidas com a biblioteca.

Para analisar as entrevistas coletadas utilizou-se o método de análise de conteúdo proposto por Bardin. A análise de conteúdo "é um método empírico, dependendo do tipo de 'fala' a que se dedica e do tipo de interpretação que se pretende como objetivo [...] é um conjunto de técnicas de análise das comunicações” (BARDIN, 2016, p. 36-37). Esse tipo de análise "visa o conhecimento de variáveis de ordem psicológica, sociológica, histórica, etc., por meio de um mecanismo de dedução com base em indicadores reconstruídos a partir de uma amostra de mensagens particulares" (BARDIN, 1977, p. 44). 
Após as considerações e dando continuidade à resolução dos objetivos, em relação ao objetivo e) propor diretrizes para o desenvolvimento desse acervo, as informações coletadas nas entrevistas serão cotejadas com a literatura levantada em uma Revisão Sistemática da Literatura (RSL) que foi realizada na Base de dados Library Information Science Abstract (LISA). A partir desse cruzamento da literatura sobre bibliotecas prisionais e o diagnóstico e características locais da biblioteca da penitenciária, poderemos sugerir parâmetros para o desenvolvimento do acervo. Realizamos a pesquisa pelas palavras-chave "biblioteca prisional", "biblioteca cárcere", "biblioteca penitenciária", "biblioteca prisão", "biblioteca centro penitenciário", "biblioteca para apenados", "prison library”, "prison libraries”, "penitentiary library", "library for grievin", "biblioteca cárcel” e "biblioteca prisión" que poderiam ocorrer no título, resumo, palavras-chave do artigo, indexador da base e/ou texto; os tipos de documentos selecionados foram artigo, estudo de caso, material de instrução/diretrizes, relatório e relatório anual, materiais em inglês, português e espanhol; acesso ao documento na íntegra e o conteúdo que abordasse o contexto, experiências, desenvolvimento de coleções das bibliotecas prisionais. Ademais, a análise das entrevistas e a observação in loco auxiliaram para a proposta.

Além disso, as diretrizes serão pautadas nos objetivos das bibliotecas prisionais, tais como, locais que apoiam a saúde mental dos detentos, auxiliam na interação positiva entre pessoas privadas de liberdade e suas famílias, deveriam educar e reeducar os detentos para alcançar níveis espirituais, educacionais e sociais (CONRAD, 2012). 


\section{Resultados parciais}

A partir pesquisa realizada por meio da revisão sistemática de literatura, tem-se como resultado, 227 documentos, desses, 19 por meio da palavra-chave "biblioteca cárcel"; 1 pela palavra-chave "biblioteca cárcere"; 3 pela palavra-chave "biblioteca centro penitenciário"; 4 pela palavra-chave "biblioteca penitenciária"; 5 pela palavra-chave "biblioteca penitenciária"; 2 pela palavra-chave "biblioteca prisão"; 14 pela palavra-chave "biblioteca prisión"; 3 pela palavra-chave "biblioteca prisional"; 41 pela palavra-chave "library for grieving"; 26 pela palavra-chave "library penitentiary"; 3 pela palavra-chave "penitentiary library" e 106 pela palavra-chave "prison library".

Após a realização da pesquisa, os dados foram anexados em uma planilha Excel. Para verificar quais os documentos estariam presentes no corpus dessas pesquisas, alguns critérios foram elencados. Os critérios de exclusão dos materiais estavam voltados para as seguintes características: a) obras que não estavam condizentes com a temática do artigo; b) documentos que não foram encontrados na íntegra, e, c) materiais repetidos. Ao final dessa análise, o corpus documental desta pesquisa ficou em 55 materiais.

Em relação aos tipos de documentos recuperados, a maior parte é de artigos (50) e estão vinculados a revistas científicas. Entre os autores que mais publicam na área estão: Tony Stevens (dois artigos) e Vibeke Lehmann (três artigos), membro do Departamento de Correções de Madison, Estados Unidos. Em 2011 houve um maior número (7) de materiais publicados e 1977, 1980, 1981, 1985, 1988, 1989, 1993, 1995, 1997, 2000, 2003, 2004, 2005, 2006, 2007, 2008, 2011 à 2019 foram os anos em que menos materiais (1) foram publicados. Sobre pesquisas brasileiras, foram recuperados 4 documentos, todos artigos, a maioria publicada na revista brasileira Informação \& Informação, publicados de 2012 à 2017.

Em relação às palavras-chave indexadas na base de dados, as mais recorrentes são: a) prison libraries; b) libraries; c) studies; d) handicapped; e) institutional libraries; f) disadvantaged; g) isolated; h) welfare services; i) librarians. Esse resultado aponta a associcação temática das bibliotecas prisionais com as bibliotecas institucionais, pessoas desfavorecidas e serviços de assistência social.

No que tange aos outros objetivos específicos, as entrevistas foram realizadas e estão em processo de transcrição e análise. Sabe-se que Uma das etapas da análise é a criação das categorias para averiguar as respostas das entrevistas, por este motivo, três categorias foram 
criadas baseada nas perguntas desenvolvidas para o questionário e enviadas aos colaboradores do Complexo Penitenciário de Florianópolis, foram elas: 1. Acervo; 2. Serviço e 3. Acesso.

\section{Considerações finais}

As prisões nacionais e internacionais estão focadas na reabilitação dos reeducandos. Para a ação de reabilitar, o sistema prisional conta com algumas leis, recomendações e documentos que focam nos aspectos relacionados aos direitos e deveres do Estado para com a comunidade carcerária e vice-versa. Sabe-se, por meio da literatura, que alguns dos direitos sancionados não estão em práticas por inúmeros motivos voltados para a administração da unidade, falta de efetivo, falta de espaço salubre e saudável, falta de financiamento, entre outros motivos ligados a força maior.

As bibliotecas prisionais são vinculadas aos espaços de privação de liberdade, esses espaços possuem particularidades que influenciam nos serviços, acessos e acervo dessas unidades. Percebe-se por meio das análises aplicadas a esta pesquisa, que as propostas realizadas pela literatura, algumas vezes, não contemplam a realidade destas ambiências. Além disso, as bibliotecas prisionais podem ser caracterizadas de diversas formas, essa caracterização depende da necessidade informacional e do contexto em que a unidade está inserida.

A metodologia utilizada para esta pesquisa fez com que o objetivo geral e os específicos fossem alcançados com sucesso. Em relação ao objetivo geral, analisar a constituição do acervo da Biblioteca da Penitenciária de Florianópolis, percebeu-se que ferramenta utilizada para o gerenciamento do acervo é o software Biblivre; a classificação é realizada a partir da Classificação Decimal Universal proposta por Otlet e Henri La Fontaine, ambos implementado nesta Biblioteca em 2017.

Para atingir o objetivo geral desta dissertação, quatro objetivos específicos foram elencados. No que concerne ao objetivo a) descrever as condições gerais do ambiente e do acervo, compreendeu-se que a Biblioteca da Penitenciária de Florianópolis está localizada no prédio administrativo do Complexo Penitenciário de Florianópolis e compartilha o espaço com a sala dos professores, banheiros, sala da coordenação do CEJA e sala da Remição de Pena pela Leitura. 
No que se refere ao objetivo b) caracterizar as temáticas contempladas no acervo. Como citamos anteriormente, o acervo da Biblioteca da Penitenciária de Florianópolis conta com cerca de quatro mil materiais inclusos em seu software até o dia em que os questionários foram respondidos, ou seja, setembro de 2019. Os assuntos desses materiais abrangem todas as nove classes da CDU. Assuntos como, por exemplo, autoajuda, religião, romance, ficção, literatura infanto-juvenil, teologia, psicologia, entre outros.

Em relação ao objetivo c) mapear a proveniência do acervo, identificou-se que a maioria do acervo é composto por doações, em sua maioria provenientes da sociedade civil. Existem materiais que são vetados por questões de segurança dentro dos espaços de privação de liberdade, apresentamos anteriormente um referencial com aspectos referente as peculiaridades do sistema prisional em questão, a segurança estará sempre em primeiro lugar.

No que tange ao objetivo d) conhecer os critérios de seleção do acervo, pode-se perceber por meio dos formulários respondidos que os critérios de seleção e descarte utilizado pelas estagiárias da Biblioteca da Penitenciária de Florianópolis visam as perspectivas propostas pelo desenvolvimento de coleção apresentada na literatura, mas ressalta-se que não há nenhuma política de desenvolvimento de coleção instituída nessa unidade. Em consequência da não existência dessa política, foi proposto para esta dissertação o objetivo e) propor diretrizes de desenvolvimento desse acervo, que em consonância com a literatura e a respostas dos formulários foi possível elaborar algumas instruções para a criação da política de desenvolvimento de coleção voltadas para bibliotecas prisionais. 


\section{Referências}

ALMEIDA, Felipe Lima de. Reflexões acerca do direito de execução penal. Revista Liberdades, São Paulo, n. 17, p. 11-49, set. 2014. Disponível em:

<http://www.revistaliberdades.org.br/site/outrasEdicoes/outrasEdicoesExibir.php?rcon_id=21 0>. Acesso em: 22 jun. 2018.

ALMEIDA JÚNIOR, Oswaldo Francisco de; BORTOLIN, Sueli. Mediação da informação e da leitura. In: SEMINÁRIO EM CIÊNCIA DA INFORMAÇÃO, 2., 2007, Londrina. Anais [...]. Londrina: EPRINTS, 2007. p. 1 - 13. Disponível em:

$<$ http://eprints.rclis.org/13269/1/MEDIA\%C3\%87\%C3\%830_DA_INFORMA\%C3\%87\%C3 \%830_E_DA_LEITURA.pdf>. Acesso em: 22 jul. 2019.

BARBOSA, Joaquim. Recomendação No 44 de 26/11/2013. Brasília. 2013. Disponível em: $<$ http://www.cnj.jus.br/busca-atos-adm?documento=1235>. Acesso em: 08 maio 2018.

BARDIN, Laurence. Análise de conteúdo. Lisboa: Edições 70, 1977.

BRASIL. [Lei Federal (1984)]. Lei No 7.210, de 11 de Julho de 1984. Institui a Lei de Execução Penal. Brasília: Presidência da República, 1984. 32 p. Disponível em: <http://www.planalto.gov.br/ccivil_03/leis/L7210.htm>. Acesso em: 18 maio 2018.

BRASIL. [Decreto (2007)]. Decreto No 6049, de 27 de Fevereiro de 2007.

Aprova o Regulamento Penitenciário Federal. Brasília: Presidência da República, 2007. Disponível em: <http://www.planalto.gov.br/ccivil_03/_ato2007-

2010/2007/decreto/d6049.htm>. Acesso em: 07 maio 2018.

BRASIL. [Lei Federal (2011)]. Lei $\mathbf{N}^{\mathbf{0}}$ 12.433, de 29 de Junho de 2011. Altera a Lei ${ }^{\mathbf{o}}$ 7.210, de 11 de julho de 1984 (Lei de Execução Penal), para dispor sobre a remição de parte do tempo de execução da pena por estudo ou por trabalho. Brasília: Presidência da República, 2011. Disponível em: 〈http://www.planalto.gov.br/ccivil_03/_ato2011-

2014/2011/lei/112433.htm>. Acesso em: 04 maio 2018

BRASIL. Constituição da República Federativa do Brasil: texto constitucional promulgado em 5 de outubro de 1988, com as alterações determinadas pelas Emendas Constitucionais de Revisão nos 1 a 6/94, pelas Emendas Constitucionais nos 1/92 a 91/2016 e pelo Decreto Legislativo no 186/2008. Brasília: Senado Federal; Coordenação de Edições Técnicas, 2016. 496 p. Disponível em:

<https://www2.senado.leg.br/bdsf/bitstream/handle/id/518231/CF88_Livro_EC91_2016.pdf>. Acesso em: 07 jun. 2018.

BRASIL. Plano nacional bibliotecas da escola: leitura e biblioteca nas escolas públicas brasileiras. Brasília: MEC, 2008. 136 p. Disponível em:

<http://portal.mec.gov.br/seb/arquivos/pdf/Avalmat/livro_mec_final_baixa.pdf>. Acesso em: 01 nov. 2018.

CARVALHO, Cristina de; CARVALHO, Marcelo Dias de. Projetos de mediação de leitura e bibliotecas em presídios femininos. Revista Brasileira de Educação em Ciência da Informação, Rio de Janeiro, v. 4, n. 1, p.136-163, jan. 2017. Disponível em: 
$<$ http://abecin.org.br/portalderevistas/index.php/rebecin/article/view/60. Acesso em: 30 abr. 2018.

CONSElHO NACIONAL DO MINISTÉRIO PÚBLICO. A visão do Ministério Público sobre o sistema prisional brasileiro - 2016. Brasília: CNMP, 2016. 344 p. Disponível em: <http://www.cnmp.mp.br/portal/images/Publicacoes/documentos/2016/Livro_sistema_prision al_web_7_12_2016.pdf>. Acesso em: 26 mar. 2019.

COSTA, Amabile. Biblioteca da penitenciária de Florianópolis: um espaço sociocultural e educativo. 2017. 78 f. Trabalho de Conclusão de Curso (Graduação em Biblioteconomia Habilitação em Gestão da Informação) - Universidade do Estado de Santa Catarina, Florianópolis, 2017. Disponível em:

〈http://sistemabu.udesc.br/pergamumweb/vinculos/000048/0000484d.pdf > . Acesso em: 25 mar. 2019.

CNJ. Banco Nacional de Monitoramento das prisões. Brasília: Conselho Nacional de Justiça, 2018. 100 p. Disponível em:

<https://www.cnj.jus.br/files/conteudo/arquivo/2018/08/57412abdb54eba909b3e1819fc4c3ef 4.pdf $>$. Acesso em: 17 ago. 2019.

CONRAD, Suzanne. Collection development and circulation policies in prison libraries: an exploratory survey of librarians in US correctional institutions. The Library Quarterly, [s.l.], v. 82, n. 4, p. 407-427, out. 2012. Disponível em:

$<$ https://www.researchgate.net/publication/258438740_Collection_Development_and_Circula tion_Policies_in_Prison_Libraries_An_Exploratory_Survey_of_Librarians_in_US_Correction al_Institutions>. Acesso em: 12 set. 2018.

FRANCO, Paki Venegas; CERVERA, Julia Pérez. Manual para o uso não sexista da linguagem: o que bem se diz... bem se entende. Minas Gerais: UNIFEM, 2006. 73 p. Disponível em: <http://www.observatoriodegenero.gov.br/menu/publicacoes/outros-artigosepublicacoes/manual-para-o-uso-nao-sexista-da-linguagem>. Acesso em: 15 ago. 2018.

GOMES, Henriette Ferreira. A mediação da informação, comunicação e educação na construção do conhecimento. Datagramazero: Revista de Ciência da Informação, v. 9, n. 1, p. 01-15, fev. 2008. Disponível em:

<http://repositorio.ufba.br:8080/ri/bitstream/ri/3041/1/DataGramaZero\%20-

\%20Revista\%20de\%20Ci\%c3\%aancia\%20da\%20Informa\%c3\%a7\%c3\%a3o\%20-

\%20Henriette.pdf>. Acesso em: 02 jul. 2019.

MALAQUIAS, Josinaldo José Fernandes. Informação e cidadania na penitenciária e Presídio do Roger. 1999. 152 f. Dissertação (Mestrado em Ciência da Informação) Universidade Federal da Paraíba, João Pessoa, 1999. Disponível em:

<https://repositorio.ufpb.br/jspui/handle/123456789/11660>. Acesso em: 26 mar. 2019.

ONU. Declaração universal dos direitos humanos. Paris: ONU, 1948.7 p. Disponível em: <http://www.ohchr.org/EN/UDHR/Documents/UDHR_Translations/por.pdf>. Acesso em: 07 jun. 2018.

PELANDRÉ, Nilcéa Lemos. Ensinar e aprender com Paulo Freire: 40 horas 40 anos depois. Florianópolis: Ed. da UFSC, 2009. 218 p. 
VERGUEIRO, Waldomiro de Castro Santos. Desenvolvimento de coleção. São Paulo: Polis, 1989. $96 \mathrm{p}$.

RANGEL, Anna Judith. Violações aos direitos humanos dos encarcerados no Brasil: perspectiva humanitária e tratados internacionais. JUSBRASIL, p.1-14, jan. 2014. Disponível em: <https://ninhajud.jusbrasil.com.br/artigos/123151293/violacoes-aos-direitos-humanosdos-encarcerados-no-brasil-perspectiva-humanitaria-e-tratados-internacionais >. Acesso em: 21 jun. 2019.

ROMÁN, Antonio Martín. A influência da leitura no contexto de encarceramento e o marco jurídico das bibliotecas prisionais. Cadernos de Informação Jurídica, Brasília, v. 5, n. 2, p.43-67, jul. 2018. Disponível em:

<http://www.cajur.com.br/index.php/cajur/issue/view/11/showToc>. Acesso em: 03 jun. 2019.

SILVA NETO, Epitácio Gomes; LEITE, Francisca Chagas Dias. Bibliotecas prisionais enquanto espaços para o acesso à informação e à cidadania. Biblos: Revista do Instituto de Ciências Humanas e da Informação, Rio Grande, v. 25, n. 1, p.47- 58, jan. 2011. Disponível em: 〈https://www.seer.furg.br/biblos/article/view/1945\&>. Acesso em: 30 jun. 2018.

Artigo submetido em: 21 nov. 2019

Artigo aceito em: 18 dez. 2019 